\title{
Acceptance Survey of GM Food in China
}

\author{
Y. T. Shao, H. J. Cai, G. Chen \\ Zhejiang University of Finance \& Economics, Xueyuan street, Hangzhou, China \\ *Corresponding author: modellover@sina.cn
}

Received September 12, 2014; Revised October 25, 2014; Accepted October 29, 2014

\begin{abstract}
The safety issue of genetically modified (GM) food has been controversial for several decades. China is a major GM food import, production and consumption country which accounts for almost $20 \%$ of the world's population. This article analyzes the present situation of China's GM food based on domestic consumer behavior, market behavior and government behavior. A wide range of public polls and markets research were taken to collect data of GM food. The roots of GM food develop and some improvements are also discussed in this study.
\end{abstract}

Keywords: GM food, food safety, present situation, root cause, improvements, China

Cite This Article: Y. T. Shao, H. J. Cai, and G. Chen, “Acceptance Survey of GM Food in China.” Journal of Food and Nutrition Research, vol. 2, no. 11 (2014): 846-849. doi: 10.12691/jfnr-2-11-14.

\section{Introduction}

A supermarket in Lanzhou, Gansu province, to be the first city in China to implement labeling of GM food counters selling on January 2, 2014 [1]. Before this time kinds of GM food are sold widely in China for many years, but few have labeled. According to a report in People's Daily July 30, 2014, five kinds of rice were detected randomly in a supermarket in Wuhan, Hubei province, and three kinds of rice contain GMO BT63. (Bacillus thuringiensis) $\mathrm{BT}$ is one alternative to chemical pesticide [2]. BT63 GM rice was developed and patented by Huazhong Agricultural University. It received "GM organism safety certification" in 2009, but has yet to get approval for commercial production. This report has caused rice sale reduce $80 \%$ in many supermarkets in Wuhan. As the volume of GM foods increases in international trade, GM grains that have not been authorized for human consumption have accidentally been comingled in food and feed supplies [3].

The GM food is most commonly used to refer to crop plants created for human or animal consumption using the latest molecular biology techniques. These plants have been modified artificially to enhance desired traits such as increased resistance to herbicides or improved nutritional content. The enhancement of desired traits has traditionally been undertaken through breeding, but this method is time consuming and inaccurate. Genetic engineering, on the other hand, can create plants with the exact desired trait very rapidly and accurately. Creating a GM crop is not particularly difficult, in fact what is expensive is to do the safety tests that all national governments require [4]. Genetically modified organisms (GMO) genes are obtained by GM technology, and GM food is processed from GMO as raw material. GMO has many advantages compared to non-GMO such as pest resistance, herbicide tolerance, disease resistance, cold tolerance, drought tolerance, salinity tolerance, nutrition malnutrition, pharmaceuticals and phytoremediation [5]. Also include disadvantages such as environmental hazards, unintended harm to other organisms, reduced effectiveness of pesticides, human health risks, allergenicity, unknown effects on human health and economic concerns [6]. GM crops are now grown in 28 countries on 170 million hectares, with more than $50 \%$ of this area in various developing countries, including China [7].

\section{Materials and methods}

Public opinion surveys and markets research were taken in six main cities distributed in different provinces in China as shown in Figure 1 (Harbin, Qingdao, Xi'an, Hangzhou, Chongqing, Kunming), on the consumers' attitude and market share of GM food. The participants of this survey included teachers and students, doctors and nurses, workers and peasants, assistants and freelancers in different age groups, and the research sites included supermarkets, emporiums, farmers markets, fruit/vegetable markets in different areas and zones. The questions were as it is shown in Table 1.

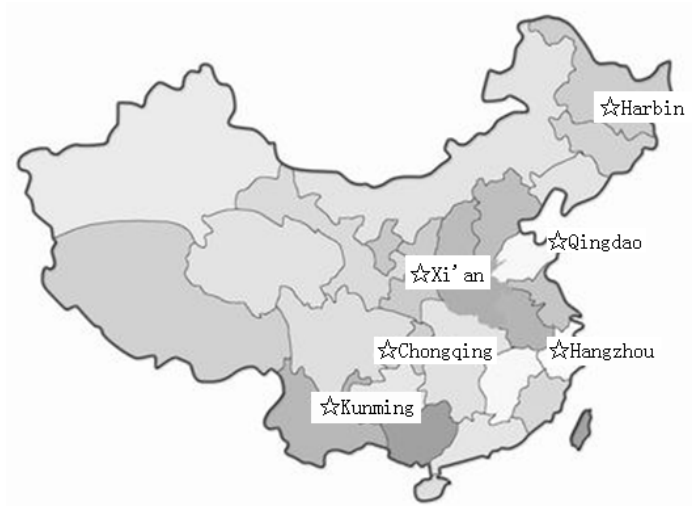

Figure 1. Main survey cities distribution map in China 
Table 1. Questionnaire of public opinion surveys of GM food China, 2014

\begin{tabular}{|c|}
\hline \multicolumn{1}{|c|}{ 1. What do you know about GM food? } \\
\hline 2. Do you accept GM food? \\
\hline 3. Can you distinguish between GM food and non-GM food? \\
\hline 4. What do you most concern about food when you are shopping? \\
\hline 5. Do you have any suggestions of GM food? \\
\hline $\begin{array}{c}\text { 6. Please fill in your personal information including age, sex, profession } \\
\text { and educational background }\end{array}$ \\
$\begin{array}{l}\text { Let's care about food safety and build a harmonious society! Thanks for } \\
\text { your support! }\end{array}$
\end{tabular}

\section{Results and Discussion}

\subsection{Results}

\subsubsection{Consumer Behavior Analyze}

A total of 958 valid questionnaires data was collected and made statistical analysis. 59\% of participants have received higher education. $87 \%$ of them have heard of GM food, while only $21 \%$ of them really know GM food. Nearly $70 \%$ of them choose non-GM food and $18 \%$ of them can accept GM food. Almost everyone can not distinguish between GM food and non-GM food only if the merchandise ticket states clearly, only $8 \%$ of them will not buy abnormally large or bright color fruits and vegetable. Over $90 \%$ of them suggest clear GM labeling. The results were as it is shown in Figure 2. The price and quality of food is the main factors for most of people when shopping, this conclusion was similar with an experiment result in European six countries which appears willing to choose GM food provided where there is a price advantage [8].

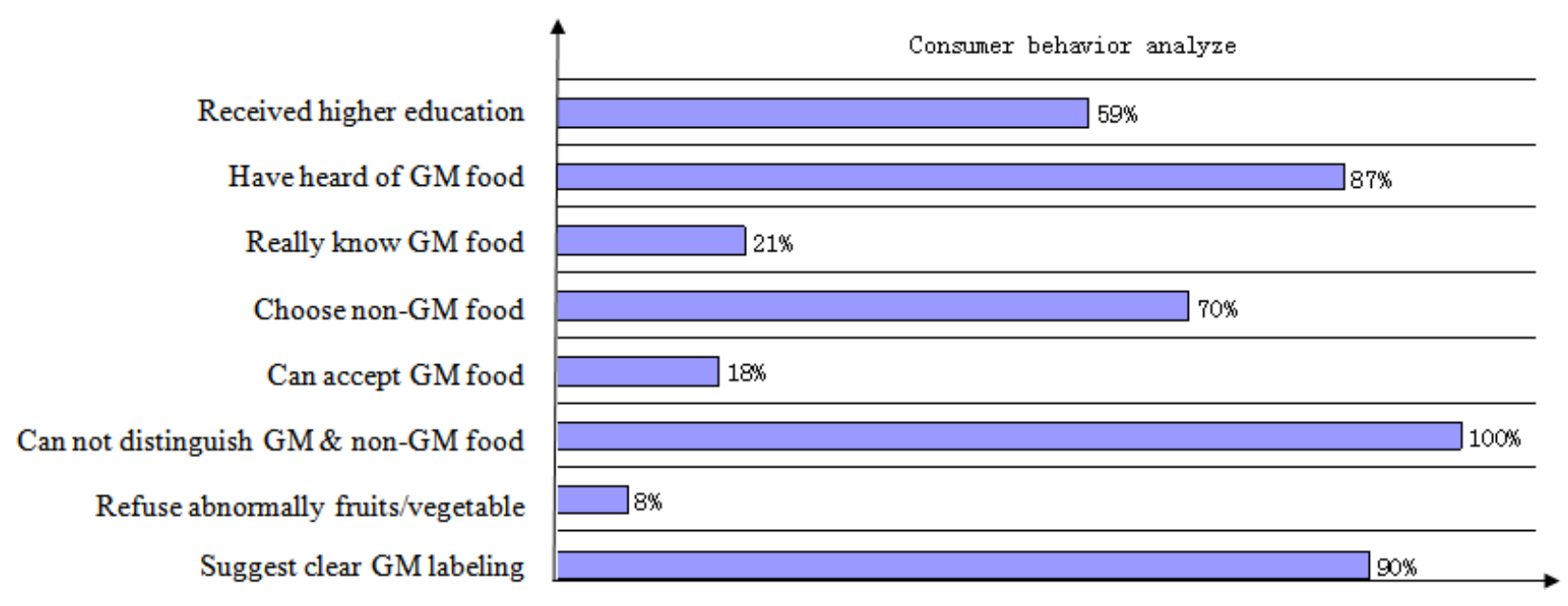

Figure 2. The results of consumer behavior analyze

\subsubsection{Markets Behavior Analyze}

A total of 68 research sites were involved in this market research. The results showed that about $85 \%$ barreled soybean oil with small font GM was labeled in kinds of markets, almost all the barreled sunflower oil, sesame oil and corn oil with big font Non-GM was labeled, while only $5 \%$ processed goods such as tofu, soy sauce, bean paste and soybean milk with Non-GM was labeled, which main raw materials is soybean, other processed goods including biscuits, soy flour, coffee, snacks, chips, instant noodles, corn starch, ketchup, bread and condiment can hardly find GM labeling. Supermarkets and emporiums have similar situation where GM and non-GM food are mixed together, and no GM food counters were set up separately and highlight with text or symbol description. Almost no GM labeling can be found in farmers markets and fruit/vegetable markets except barreled cooking oil. In fact, some kinds of agricultural products such as soybeans, corn, papaya, sugar beets, oilseed rape, rice and tomatoes are GM food.

\subsubsection{Government Behavior Analyze}

China is one of the earliest countries to develop and implement genetically modified organism (GMO) regulations in the world, many management measures and regulations were gradually introduced and implemented from 1993, especially a series of regulations include safety evaluation, import safety, biological identity, food hygiene, entry-exit inspection and quarantine which were implemented between 2001 and 2004, <Safety Assessment of GM Plants Guide> is a more complete and effective regulations which was formulated by Chinese Ministry of Agriculture in 2010. Relevant regulatory agencies involve Chinese Ministry of Agriculture, National Development and Reform Commission (NDRC), Ministry of Commerce, Ministry of Science and Technology, Ministry of Health, State Administration of Quality Supervision, State Environmental Protection Administration (SEPA) and other regulatory agencies. By implementing $<$ Regulations on Administration of Agricultural Genetically Modified Organisms Safety> (2011 Amendments), it will be for the purposes of strengthening the labeling administration of agricultural GMO, standardizing the marketing activities of agricultural GMO, guiding the production and consumption of agricultural GMO, and protecting consumers' right of full access to the information about the products. However, it is difficult to deal with the environmental risks of GM crops for government regulatory failure, one is the system failure, and the other is implementation failure [9].

\subsection{Discussion}

\subsubsection{The roots of GM Food Development in China}


a) The arable land is declining yearly while the population is growing. About 3000 to 4000 square kilometers arable land was lost in the past few years in China, while total area of arable land is about 1.2 million square kilometers in China, which includes parts of dry barren lands, saline-alkali land, hilly land and other contaminated land. The population of China will reach to 1.5 billion in 2030 [10], and it needs grain yields increase by $40 \%$.

b) The water resource is declining yearly. A major national strategic plan which invested over 1.1 billion dollars was implemented to improve water conservation issues in North China in 2014, according to Ke Bing, the president of China Agricultural University. The amount of fresh water per capita is only a quarter of the world level, and $70 \%$ of water was used in agriculture. The north and northwest in China has been relatively arid, and in addition, the destruction of vegetation in recent years also aggravated water shortages. The growth of grain crop such as wheat, corn, soybeans need plenty of water for irrigation.

c) The cost of agricultural labor is increasing progressively. The cost of agricultural labor has improved under socialist market economy compared with manual labor in the past. However, the relatively low level of farming mechanization and agricultural science and technology lead to the huge loss of agricultural labor, especially young labors (over 50\%) in grain producing areas [10].

d) Other costs of farm products are also increasing progressively. The main costs include seeds, fertilizers, pesticides, agricultural machinery and other facilities. Chinese agricultural mechanization proportion is about $48.8 \%$ in 2010 and expectation proportion to $70 \%$ in 2020 , according to Wang Mao-Hua, the Chinese Academy of Engineering. So, the cost of manual agricultural production is obviously high under the market economy.

e) Advantages of GM crops. The superior performance of GM crops hit Chinese agricultural market for it can greatly reduce cost of agricultural production, and solve the problem of feeding a population nearly 1.4 billion effectively.

\subsubsection{The Improvement Measures of GM Food Development in China}

a) Ensure the public's right to know. According to the questionnaires data, only $21 \%$ of participants really know what GM food is, others have no idea about GM food but have eaten GM food for many years. About 90\% of participants suggest labeling GM food clearly. Relevant departments and markets should ensure the public's right to know GM food.

b) Extensive propaganda GM food knowledge. According to the questionnaires data, nearly $70 \%$ of participants choose non-GM food, but only $21 \%$ of them know about GM food. The root cause of this phenomenon is that people have no idea about GM food. People can not accept strange things especially food, so they choose familiar food which they used before.

c) It is necessary to make long-term animal tests and observations before GM food is placed in markets. Food safety is prerequisites for everybody. Although animals test suggest that GM food will not do harm to rats, mice, pigs, etc $[11,12]$, but these tests lack of continuity, the results may not applicable to human body. Advanced laboratory equipment and detection technology for nutrition, marker genes, toxicology are also needed to ensure the safety of GM food.

d) Strengthen the safety management of GM food. Relevant functional departments should supervise strictly in GM food production, processing and marketing. GM research institutions should strengthen security measures and prevent disclosure of GMO seeds. Safety evaluation of crop management systems and technology system should be built. Risk-control technology and harm-against measures should be researched and developed to avoid issues such as genetic drift.

\section{Conclusion}

China is a major GM food importing, producing and consuming nation, so China's GM food safety is a very important factor to restrict or facilitate the development of the whole society. According to extensive questionnaires and market research in six main cities in China, the result shows that most consumers and retailers have no clear understanding on GM food. Therefore the public acceptance of GM food is lowly. Most kinds of GM food have no clear GM labeling except some soybean oil, edible oil, cooking oil. Although a series of GM food management measures and regulations have been made by relevant functional departments but implement difficult and low efficiency. Many factors such as land, population, water and cost affect the development of agriculture food and that made the GM food eye-catching, so it is necessary to ensure the public's right to know GM food and make a long-term test and safety management before GM food available for sale on the market.

\section{References}

[1] People's Daily (PD) News., Genetically modified foods are sold in Gansu counters more than one month. http://www.gsda.gov.cn/CL0014/34332.html, April 19, 2014, (Article in Chinese).

[2] Tang, W., Chen, H., Xu, C.G., Li, X.H., Lin,Y.J. and Zhang, Q.F., Development of insect-resistant transgenic indica rice with a syntheticcry1C* gene. Mol Breeding, 18. 1-10. 2006.

[3] Matsuo, M. and Yoshikura, H., "Zero" in terms of food policy and risk perception. Food Policy, 45. 132-137. 2014.

[4] Chrispeels, M.J., Yes indeed, most Americans do eat GMOs every day. Journal of Integrative Plant Biology, 56 (1). 4-6. 2014.

[5] Cockbum, A., Commercial plant breeding: What is in the biotech pipeline? Journal of Commercial Biotechnology, 10 (3). 209-223. 2004.

[6] Verma, C., Nanda, S., Singh, R.K., Singh, R.B. and Mishra, S., A Review on Impacts of Genetically Modified Food on Human Health. The Open Nutraceuticals Journal, 4. 3-11. 2011.

[7] James, C., Global status of Commercialized biotech/GM Crops: 2010. The International Service for the acquisition of agri-biotech applications Brief No. 42. ISAAA, Ithaca, New York, 2011.

[8] Knight, J.G., Mather, D.W., Holdsworth, D.K. and Ermen, D.F., Acceptance of GM food an experiment in six countries. Nature Biotechnology, 25 (5). 507-508. 2007.

[9] Lu, Q.F., The Regulation to Genetically Modified Crops' Industrialization Promotion: Government Failure and Public Supervision. Forum on Science and Technology in China, 2. 118123. 2014. 
[10] Liu, P.L., Zhao, Y.G., Li, N. and Zhou, Y.L., Food security and the countermeasures of GM technology. China Agricultural Science and Technology, 12 (4). 1-5. 2010.

[11] Ladics, G.S., Knippels, L.M.J., Penninks, A.H., Bannon, G.A., Goodman, R.E. and Herouet-Guicheney, C., Review of animal models designed to predict the potential allergenicity of novel proteins in genetically modified crops. Regulatory Toxicology and Pharmacology, 56 (2). 212-224. 2010.

[12] Adel-Patient, K., Guimaraes, V.D., Paris, A., Drumare, M.F., AhLeung, S., Lamourette, P., Nevers, M.C., Canlet, C., Molina, J., Bernard, H., Créminon, C. and Wal, J.M., Immunological and Metabolomic Impacts of Administration of Cry1Ab Protein and MON 810 Maize in Mouse. PloS ONE, 6 (1). 1-12. 2011. 